\title{
Biocidal properties study of silver nanoparticles used for application in green housing
}

\author{
Siim Küünal ${ }^{1} \cdot$ Sander Kutti $^{1} \cdot$ Protima Rauwel $^{2} \cdot$ Mithu Guha $^{3}$ • \\ David Wragg ${ }^{4} \cdot$ Erwan Rauwel $^{1}$
}

Received: 17 November 2015 / Accepted: 29 June 2016/Published online: 7 July 2016

(c) The Author(s) 2016. This article is published with open access at Springerlink.com

\begin{abstract}
We report on the study of surfactant-free silver nanoparticles synthesized using non-hydrolytic sol-gel methods for applications in straw bale constructions. Micro-organism infestation in green constructions is of concern as their proliferation tends to induce health problems. We demonstrate the biocidal properties of these $\mathrm{Ag}$ nanoparticles and their efficacy against fungi. Outdoor tests with Ag nanoparticles have demonstrated the effective protection of straw against micro-organisms. Indoor tests using broth liquid are compared with a method of testing we recently developed where the possible nature of the biocidal properties of the silver nanoparticles are further probed. In contrast to the commonly reported results, this study shows that Ag nanoparticles synthesized using nonhydrolytic sol-gel methods have antifungal properties against common fungi in outdoor conditions which demonstrate high potential in related applications.
\end{abstract}

Keywords Silver nanoparticles $\cdot$ Sol-gel $\cdot$ Antifungal properties · Green housing · Toxicity

Erwan Rauwel

erwan.rauwel@ttu.ee

1 Tartu College, Tallinn University of Technology, 51008 Tartu, Estonia

2 Institute of Physics, University of Tartu, Riia, Tartu, Estonia

3 Department of General and Molecular Pathology, Faculty of Medicine, University of Tartu, Tartu, Estonia

4 Department of Chemistry and SMN, University of Oslo, Oslo, Norway

\section{Introduction}

During the last decades, silver metal nanoparticles (MNPs) have spurred a lot of interest due to their conductive, optical [1], catalytic [2], and more particularly biocidal properties [3, 4]. In fact, among noble metals, Ag MNPs possess the most efficient biocidal properties with a very broad bactericidal and fungicidal activity spectrum. This specificity makes them the best candidate for developing applications in emerging areas like medicine [5], and a good candidate for applications in the ecological constructions. The importance of green housing is growing every year as ecological materials reduce the construction life cycle energy used and therefore, the environmental impact of the building construction [6]. Straw bales appear to be an ecologically friendly choice for construction due to their low cost, good acoustic [7], and thermal insulation. Nevertheless, their durability and hygroscopic properties make them suitable environments for many harmful microorganisms that can cause many diseases including fungi like Stachybotrys atra that appear to be a more important threat than bacteria [8].

The present day solutions rely on chemical products like boric acid or biotol/ammonium chloride compounds that present some drawbacks [9]. All routes to produce $\mathrm{Ag}$ MNPs have their advantages, but there are some drawbacks such as cost, scalability, pollution, size, and size distribution. Presently, a lot of effort has been put into the development of "green synthesis" methods [10]. In fact, noble metal nanoparticles synthesis based on the utilization of fungi or plant extracts has spurred a lot of investigation over the world. This paper presents investigations on the antifungal properties of Ag MNPs synthesized by facile and cheap sol-gel synthesis used as a protective agent in houses built using eco-friendly materials. 


\section{Materials and methods}

\section{Synthesis of the silver metal nanoparticles}

Ag MNPs were synthesized using non-hydrolytic sol-gel methods described elsewhere [11-13]. Silver acetate (99\%, Aldrich) precursor along with benzylamine solvent was used for the synthesis of the nanoparticles. The resulted mixture was transferred into a stainless steel autoclave and was carefully sealed. Thereafter, the autoclave was taken out of the glovebox and heated in an oven at $200{ }^{\circ} \mathrm{C}$ for $48 \mathrm{~h}$. The resulting suspensions were centrifuged and the precipitates were thoroughly washed with ethanol and subsequently dried in air at $70{ }^{\circ} \mathrm{C}$.

\section{Characterization of the nanoparticles}

X-ray diffraction (XRD) data were collected using a Bruker D8 Discover instrument equipped with a LynxEye detector. $\mathrm{Cu}(\mathrm{k} \alpha 1=1.54056 \AA)$ radiation selected by a Ge (111) monochromator was used. The crystallite size was calculated from the XRD data using full profile Scherrer methods in TOPAS, with a fundamental parameters peak shape. A Pawley fit based on the lattice parameter for cubic silver was used. The thermal history of the silver nanoparticles was studied under air from room temperature to $800{ }^{\circ} \mathrm{C}$ using a Rheometric Scientific STA 1500 Thermogravimetric analysis (TGA) instrument. Transmission electron microscopy (TEM) studies were carried out on a probe corrected Titan G2 $80-200 \mathrm{kV}$ operating at $200 \mathrm{kV}$. The point to point resolutions in TEM and STEM modes are 2.4 and $0.9 \AA$. X-ray photoelectron spectroscopy (XPS) analysis was carried out on a Kratos Analytical Axis UltraDLD photoelectron spectrometer equipped with $\mathrm{Al} \mathrm{K}_{\alpha}$ $\mathrm{X}$-ray source. Liquid broth conditions and agar plate preparation can be found in [9].

\section{Liquid broth tests}

Different concentrations ranging from $100 \mathrm{mg} / \mathrm{L}$ to $1 \mathrm{~g} / \mathrm{L}$ of Ag NPs were crushed and dispersed into the liquid broth medium composed of maltose and Chloramphenicol. Then after Aspergillus spp. was added to the mixture. Continuous magnetic stirring was performed for $24 \mathrm{~h}$, i.e., during the whole experiment to homogenize the solution of dispersed Ag MNPs.

\section{Coating of the straw bales}

Ethanol solutions containing different silver nanoparticle concentrations were prepared by dispersion of the $\mathrm{Ag}$ nanoparticles (10 and $40 \mathrm{mg} / \mathrm{L}$ ) in pure ethanol. The dispersion was improved using a magnetic stirring for 2 days combined with stay in an ultrasonic bath at $35{ }^{\circ} \mathrm{C}$ for 30 min to disperse them homogeneously in the solution. The straw bales were dipped for $1 \mathrm{~h}$ into the ethanol solution after dispersion and then taken from the vessel for drying under air. The use of a magnetic stirrer enables homogeneous decoration of the straw with $\mathrm{Ag}$ MNPs. Then, the straw bale samples were placed into aggressive outdoor conditions for 18 days covered from direct rainfall and sunlight. The samples were then cut and printed into agar plates for $72 \mathrm{~h}$ under $32{ }^{\circ} \mathrm{C}$ for microorganism staining and identification.

\section{Identification}

For identification, the microorganisms were heat fixed on microscope slides. The fungal cells were stained using $5 \%$ bengal red solution. To acquire better visualization, all of the fungal slides were stained three times. After drying of the slides, the identification was carried out via microscopy using online databases. To check whether bacteria were Gram-positive or Gram-negative, the bacteria were stained using Gram's method as described by the manufacturer (Sigma-Aldrich).

\section{Toxicity study}

Different concentrations of nanoparticles were studied via MTT assay (M). Human embryonic kidney (HEK) cells [14] were seeded on day 0 at a density of 1000 per well in 96-well microtiter plates. On day 1, silver nanoparticle at different concentration was added. After $24 \mathrm{~h}$ incubation, the medium containing nanoparticles was removed from the plate to make sure that no nanoparticles remain in the solution and avoid overlap or hinder MTT assay. After 24 h, 3-(4,5-dimethylthiazol-2-yl)-2,5-diphenyltetrazolium bromide (MTT) was added to each well $(0.5 \mathrm{mg} / \mathrm{mL}$; Sigma-Aldrich), and plates were maintained at $37^{\circ} \mathrm{C}$ for $2 \mathrm{~h}$. The medium was then discarded, and DMSO was added to each well to lyse the cells. Absorbance was measured at $450 \mathrm{~nm}$ using a multiwall spectrophotometer (Tecan, microplate reader). All MTT assay were repeated twice.

\section{Discussion}

The utilization of $482 \mathrm{mg}$ of silver acetate precursor enabled the production of $296.7 \mathrm{mg}$ of pure Ag MNPs giving an average reaction yield of $95.15 \pm 5 \%$ that was calculated with five syntheses. This shows that the reaction process is very efficient and economically interesting. Figure 1 shows a typical XRD pattern of the prepared Ag nanoparticles. It can be clearly seen from the XRD pattern 


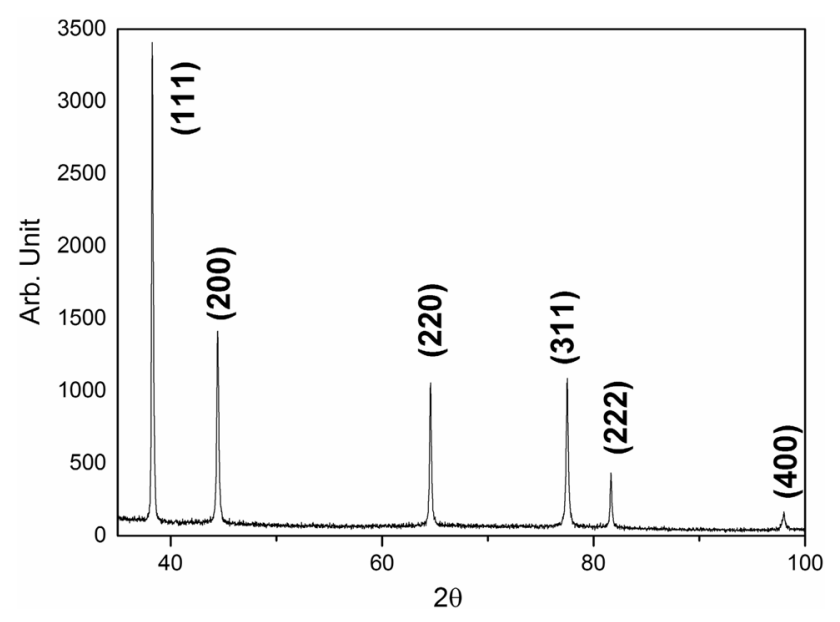

Fig. 1 XRD pattern of cubic silver nanoparticles

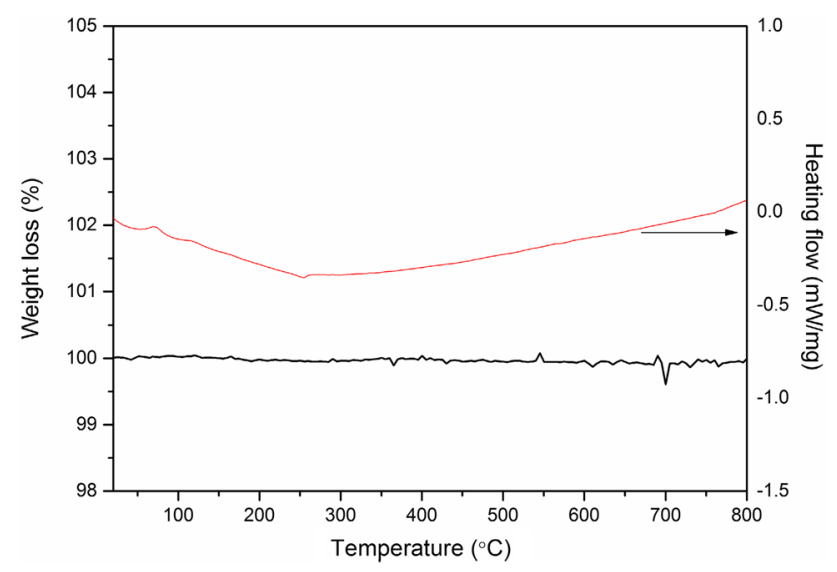

Fig. 2 TGA and DTA performed under $\mathrm{N}_{2}$ of silver nanoparticles

that the Ag NPs are single phase nature and only exhibit the characteristic diffraction peaks of the $\mathrm{Ag}$ metal cubic structure (JCPDS File No 87-0720). No secondary phase of silver oxide structure was detected by XRD and the high intensity of the XRD peaks indicates that the Ag NPs are highly crystalline.

Thermogravimetric analysis was performed on the $\mathrm{Ag}$ nanoparticles to evaluate their purity and estimate the amount of organic species adsorbed on the silver nanoparticle surface and their resistance against oxidation under air. Typical thermogram in Fig. 2, does not show any weight loss or gain during the whole measurement till $800{ }^{\circ} \mathrm{C}$, suggesting the absence of organic species on the surface (surfactant-free) and the high stability against oxidation. Differential thermal analysis (DTA) shows a very slight decrease of the heat capacity $(-0.4 \mathrm{~mW} / \mathrm{mg})$ with the increase of the temperature that could be attributed to a probable aggregation of the Ag MNPs together.

The morphology and size distribution of Ag nanoparticles were also studied by (S)TEM. The HAADF-STEM electron micrograph in Fig. 3a gives an overview of the nanoparticles. The size distribution of the nanoparticles lies within a range of 5-20 nm. A few larger particles were also observed with sizes of around $50 \mathrm{~nm}$. The HRTEM image in Fig. $3 \mathrm{~b}$ is of a $10 \mathrm{~nm}$ crystalline $\mathrm{Ag}$ nanoparticle oriented along the [110] zone axis of the Fm-3 m cubic structure with a lattice parameter of $0.4 \AA$.

XPS measurements were performed on Ag MNPs to confirm their purity and study the nature of their surface. XPS study was performed 6 months after the synthesis of the Ag NPs that were stored in the powder form under ambient air. Figure 4 presents the XPS survey spectra, showing only binding energy peak from $\mathrm{Ag}$ metal [15] and no visible peak of nitrogen (see inset) or oxygen. The carbon binding energy peak is certainly due to air contamination that cannot be avoided. Due to the nanosize of the Ag MNPs and the high surface to volume ratio, any oxidation of the Ag MNPs surface would be detected by XPS analysis. The position of the Auger peak corresponds here to metallic silver. In addition, the $\mathrm{Ag} 3 \mathrm{~d} 5 / 2$ photoelectron peak corresponds to metal $\mathrm{Ag}$ $(368.3 \mathrm{eV})$, thus confirming the purity and the metal nature of $\mathrm{Ag}$ MNPs. The XPS study then confirm the purely metallic nature of these Ag NPs and their high stability against oxidation.

Two methods to test the biocidal properties of Ag were used: broth liquid solution and decoration of the straw with Ag MNPs dispersed in ethanol solutions at different concentrations. The antifungal study based on broth dilution assay on Aspergillus spp. showed that this method was not an adapted one as the Ag MNPs are surfactant-free. In fact, the broth medium contains amino acids that contain several chains of sulfur groups and these groups are able to bond on Ag MNPs surface and then passivate them, neutralizing their biocidal properties. For this reason we have developed a second method that consists of immersing the straw samples into a vessel filled with a solution containing $\mathrm{Ag}$ MNPs dispersed in ethanol for $1 \mathrm{~h}$ under magnetic stirring and then taken out for drying under air. A ratio of $1 \mathrm{mg}$ and $2.5 \mathrm{mg}$ of Ag MNPs for $1 \mathrm{~g}$ of straw were dispersed in ethanol. Previous tests showed that concentration of $100 \mathrm{mg} / \mathrm{L}$ of Ag NPs was sufficient to observe a biocidal effect [11]. Two reference samples where straw samples dipped into pure ethanol or water were also prepared. The four samples were covered and contaminated by placing them in outdoor conditions for 21 days. Covering them ensured protection from direct sunlight and rainfall during the month of May which most probably also promoted the rapid development of microorganisms. After 3 weeks, some straws were taken from each straw bale and deposited directly onto the agar plates [11] and printed into agar plates for $72 \mathrm{~h}$ at $25{ }^{\circ} \mathrm{C}$ for microorganisms staining and identification. 
Fig. 3 a STEM image overview of $\mathrm{Ag}$ nanoparticles dispersed on a carbon grid. b HRTEM image of Ag nanoparticle oriented along [110] zone axis
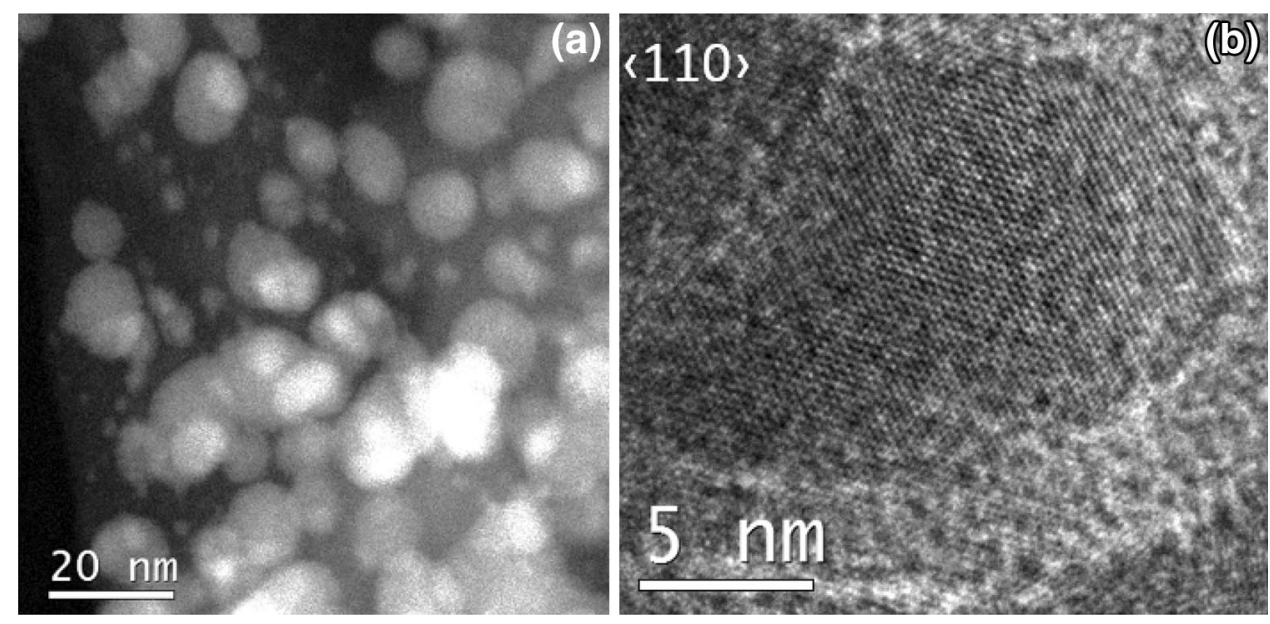

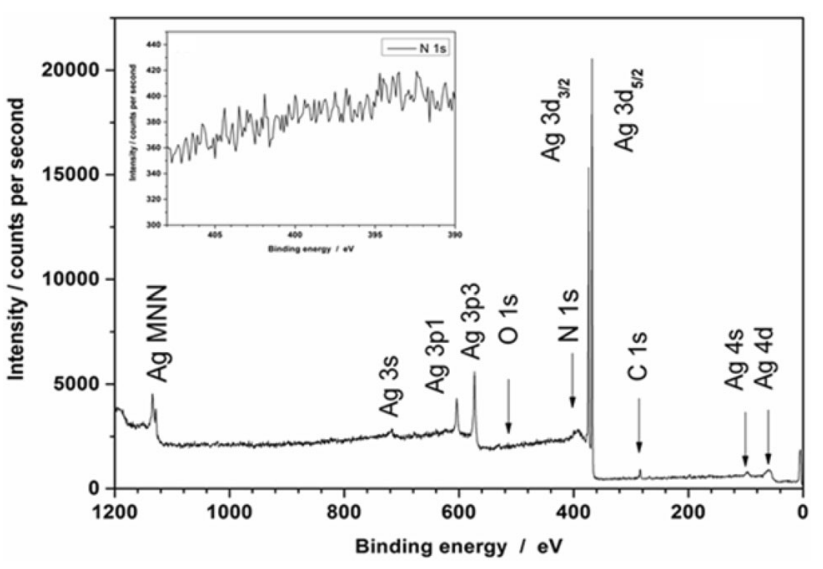

Fig. 4 XPS survey of $\mathrm{Ag}$ MNPs, inset shows the absence of $\mathrm{N}$ binding energy peak

From the first observation, bacteria were present on all straw samples due to the highly nutritious agar which promoted the growth of bacterial colonies; Gram-positive and Gram-negative bacteria were equally represented and no specific effect on one particular bacterial group was witnessed (Fig. 5). However, the agar plates which contained straws treated with silver nanoparticles, showed differences in the straw surface (color and smoothness) compared to untreated counterparts (Fig. 5c, d). Untreated straw displayed color change due to the direct growth of colonies on the straw surface. Additionally, treated samples did not contain any visible fungal activity that was observed in the case of untreated and only ethanol-treated straw. In fact, fungi need less favorable conditions including low moisture content to grow in houses [15]; therefore, the absence of fungi in this study was rewarding.

Penicillum spp. and Cladosporium spp. were clearly identified on untreated and ethanol-treated straw (Fig. 5).These fungi species are known to produce hazardous mycotoxins, which compromise the health of house

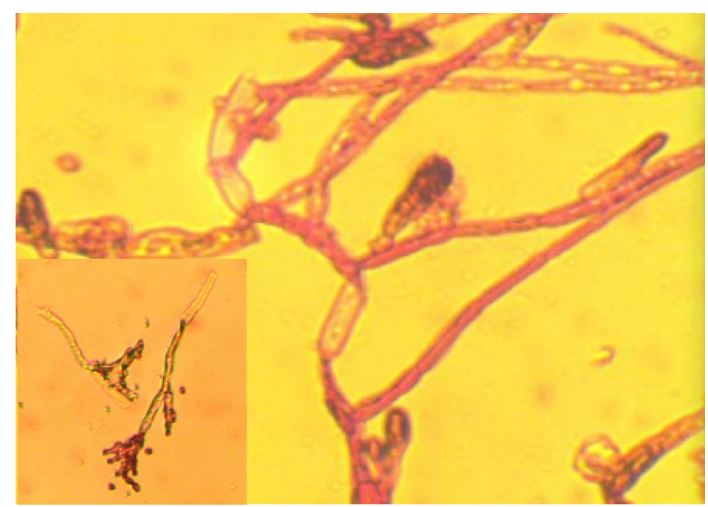

Fig. 5 Penicillium hyphae and conidiophore (small picture) isolated from untreated straw

residents due to their allergenic and probably even carcinogenic properties [16, 17]. Moreover, some fungal spores retain their toxicity even after their death, indicating that threat to health is persistent once mold has grown on the building material. The difference is clearly displayed in Fig. 6, where straw bale samples treated with ethanol solution containing 1 and $2.5 \mathrm{mg}$ of Ag MNPs per gram of dry straw showed less microorganism growth on the straw surface and complete absence of fungal growth on the plates.

The antimicrobial mechanism of silver nanoparticles is not yet fully understood; however, experimental data suggest a combination of multiple effects on microorganisms that can occur simultaneously or separately [16-21]. In addition, the experimental evidence also shows that silver nanoparticles are normally more effective against bacteria than fungi [22]. Fungi are eukaryotes and have more resistant cell boundaries viz., a cell wall, which consists of hard substance called chitin. Compared to bacteria, fungal cells should in principle be less affected by silver nanoparticles. However, for the series of outdoor tests, we 
Fig. 6 Straw printed to the plate count agar (PCA) after $72 \mathrm{~h}$ at $25^{\circ} \mathrm{C}$, a untreated straw, b straw soaked with ethanol, c straw treated with $1 \mathrm{mg}$ of silver nanoparticles per gram of dry straw, d straw treated with $2.5 \mathrm{mg}$ of silver nanoparticles per gram of dry straw
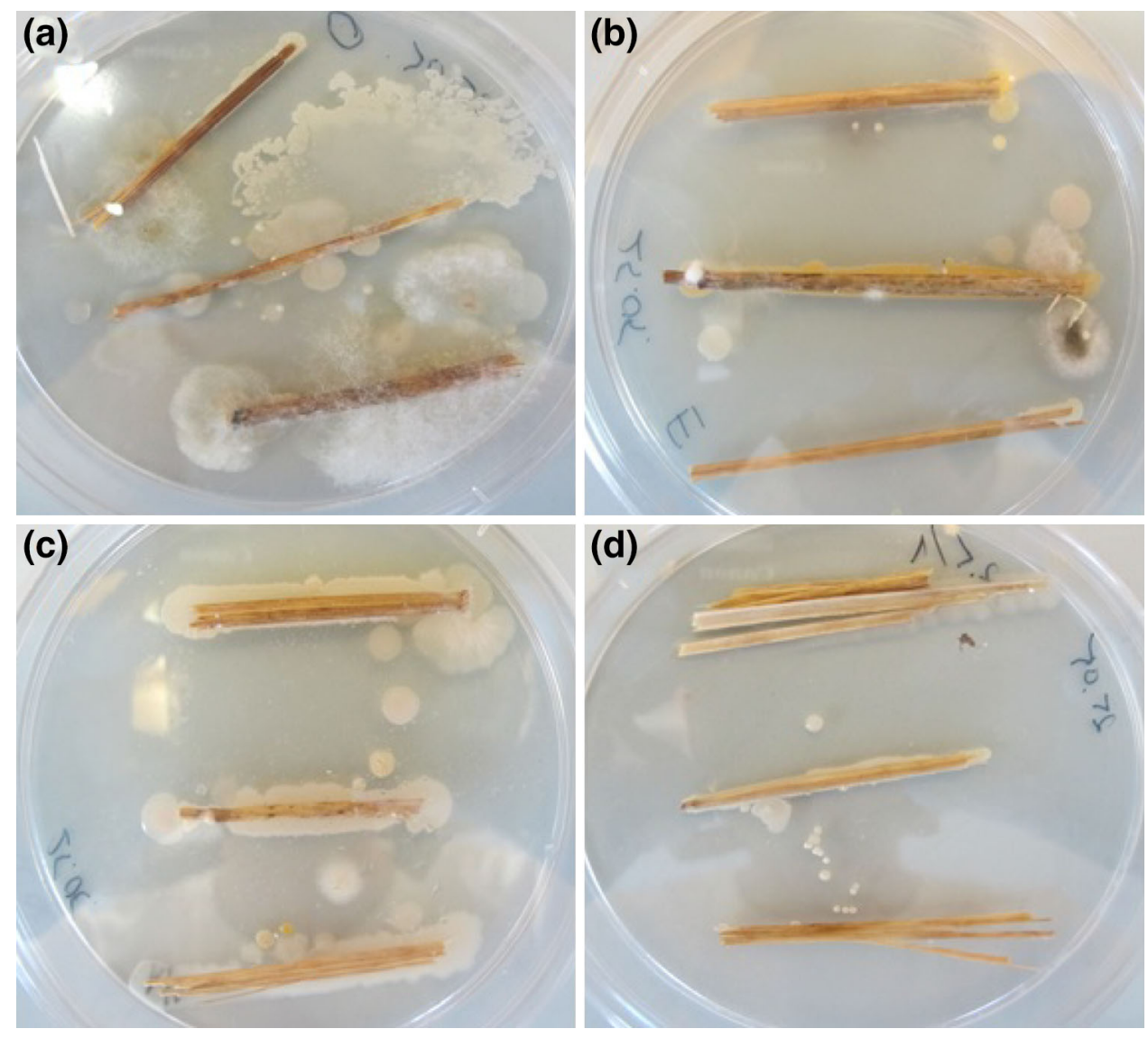

observed that typical bacteria that colonize straw seem to be less sensitive to the Ag MNPs than the typical strawcolonizing fungi.

Due to the metallic nature of the surface of the nanoparticles and the absence of oxidized silver on their surface, the most probable origin of the biocidal properties is through direct contact. In fact, no Ag cation could be released from a purely metallic surface. Nevertheless, one explanation of this phenomenon implies that bacterial colonies have the capacity to grow a protective biofilm around them, when facing aggressive environment. This biofilm is usually not produced in agar plates as they tend to be in a highly favorable environment. This biofilm is not easily penetrable and, therefore, can provide protection to colonies against Ag MNPs. On the flip side, the biofilm also self-limits the growth and expansion of the bacterial colonies. This is further manifested by the clean surfaces of the treated straw, not affected by bio-organisms. The latter demonstrates that $\mathrm{Ag}$ nanoparticles can inhibit the growth of biofilm protected colonies by confining them to only certain areas and curbing their proliferation. Furthermore, the absence of color change on the straw treated with silver nanoparticles supports the claim that silver nanoparticles specifically inhibit fungal development. Absence of fungal colonies on the agar plates, which contained silver

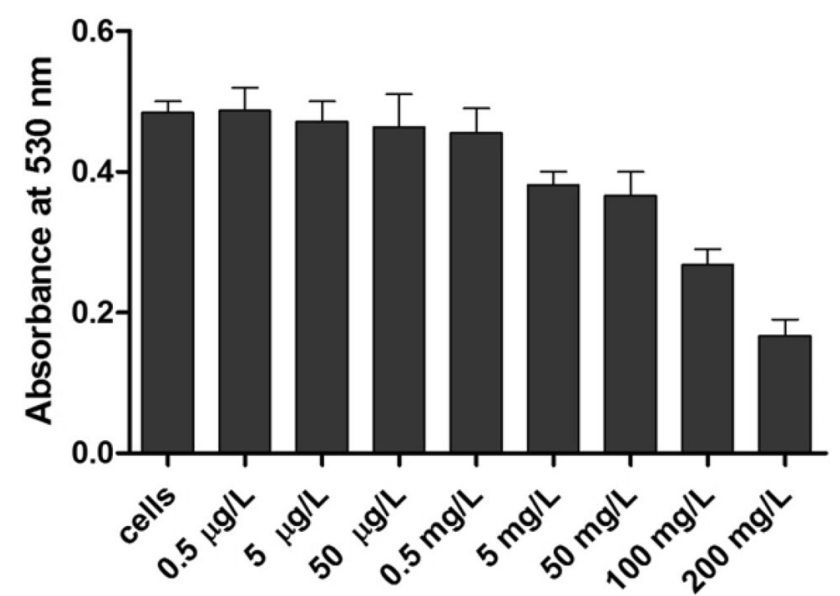

Fig. 7 Toxicity test of silver metal nanoparticles on human HEK cells

nanoparticle-treated straw, can be explained by the fact that these fungal colonies cannot generate protective biofilm layers around them. Contrary to the results of our experiment, in real life environmental stress conditions fungi tend to dominate over bacterial colonies because they need less suitable conditions to proliferate [15]. As a result, fungi are more problematic within the walls of residential buildings. This study shows that Ag MNPs dispersed in ethanol can 
Table 1 Result of MTT assay test

\begin{tabular}{lllllllll}
\hline Concentration of Ag MNPs & 0 & $5 \mu \mathrm{g} / \mathrm{L}$ & $50 \mu \mathrm{g} / \mathrm{L}$ & $0.5 \mathrm{mg} / \mathrm{L}$ & $5 \mathrm{mg} / \mathrm{L}$ & $50 \mathrm{mg} / \mathrm{L}$ & $100 \mathrm{mg} / \mathrm{L}$ & $200 \mathrm{mg} / \mathrm{L}$ \\
Cells survivability & 0.4680 & 0.4420 & 0.4167 & 0.4197 & 0.3627 & 0.3313 & 0.2457 & 0.1427 \\
\hline
\end{tabular}

be a promising ecological option for the protection of straw bales that are used in eco-housing and leading a healthy lifestyle and taking into account that the cost of treatment Ag treatment is similar to conventional chemical treatment in straw bales.

Before using these silver nanoparticles as antibacterial and antifungal treatment for the protection of straw bales, it is necessary to study the toxicity of these Ag MNPs against human cells. HEK cells are very commonly used for testing the toxicity of metal nanoparticles [23]. Therefore, the cytotoxicity of these Ag MNPs was investigated on HEK cells. Different concentrations of Ag MNPs dispersed in PBS solution were studied by MTT assay. Figure 7 shows MTT assay performed on $\mathrm{Ag}$ MNPs solutions of concentration ranging from 10 to $200 \mathrm{mg} / \mathrm{L}$. Figure 7 shows the mean \pm SEM of duplicate measurements of a representative sample of three independent experiments. This toxicity study toward HEK cells shows that mortality rate is over $50 \%$ only for very high concentration of silver nanoparticles $(200 \mathrm{mg} /$ L). For a lower concentration, the Ag MNPs are not toxic to human cells (Table 1), which makes them a suitable material for antimicrobial and antifungal treatment applications.

\section{Conclusion}

This study supports the fact that the origin of the biocidal properties of the Ag MNPs produced by non-hydrolytic sol-gel method is related to direct contact of the Ag MNPs with the micro-organisms. In fact, these Ag MNPs are surfactant-free and their surface is metallic preventing ion release in the medium. In addition, fungal species were more affected than bacterial colonies that can produce protective biofilm. These results suggest that it is possible to apply Ag MNPs in ecological straw bale construction as a protective agent. MTT assay toxicity showed that these Ag NPs are only toxic for high concentrations. Unlike several chemical repellents, which are toxic to human health and degrade over time, Ag MNPs represent a cheaper, harmless, and more permanent solution for ecofriendly house development.

Acknowledgments The authors wish to acknowledge the Estonian Research Council (Grant PUT431), the European Regional Development Fund project TK134 (TAR16019), Marie Curie grant (PERG05-GA-2009-249243), the Norwegian Research Council, the Estonian Road Map infrastructure, and the NAMUR projects for financial support of this work. We express our thanks to Mr. M. F. Sunding for XPS analysis.
Open Access This article is distributed under the terms of the Creative Commons Attribution 4.0 International License (http://crea tivecommons.org/licenses/by/4.0/), which permits unrestricted use, distribution, and reproduction in any medium, provided you give appropriate credit to the original author(s) and the source, provide a link to the Creative Commons license, and indicate if changes were made.

\section{References}

1. Zijlstra, P., Orrit, M.: Single metal nanoparticles: optical detection, spectroscopy and applications. Rep. Prog. Phys. 74, 106401 (2011)

2. $\mathrm{Hu}, \mathrm{C}$., Lan, Y., Qu, J., Hu, X., Wang, A.: Ag/AgBr/TiO 2 Visible Light Photocatalyst for Destruction of Azodyes and Bacteria. J. Phys. Chem. B: 110, 4066-4072 (2006)

3. Uttayarat, P., Eamsiri, J., Tangthong, T., Suwanmala, P.: Radiolytic Synthesis of Colloidal Silver Nanoparticles for Antibacterial Wound Dressings. Adv. Mater. Sci. Eng. 2015, 6 (2015)

4. Jeong, Y., Lim, D.W., Choi, J.: Assessment of Size-Dependent Antimicrobial and Cytotoxic Properties of Silver Nanoparticles. Adv. Mater. Sci. Eng. 2014, 6 (2014)

5. Rai, M., Yadav, A., Gade, A.: Silver nanoparticles as a new generation of antimicrobials. Biotechnol. Adv. 27, 76-83 (2009)

6. Henderson, K.: Achieving legitimacy: visual discourses in engineering design and green building code development. Build. Res. Inf. 35, 6-17 (2007)

7. Deverell, R., Goodhew, S., Griffiths, R., de Wilde, P.: The noise insulation properties of non-food-crop walling for schools and colleges: A case study. J. Build. Apprais. 5, 29-40 (2009)

8. Fog Nielsen, K.: Mycotoxin production by indoor molds. Fungal Gen. Biol. 39, 103-117 (2003)

9. Lebow, S.T.: Wood preservation. In: Wood Handbook, Wood as an Engineering Material, Chap. 15, p. 6. U.S. Department of Agriculture, Forest Service, Forest Products Laboratory, Centennial Edition, Madison, Wisconsin (2010)

10. Rauwel, P., Küünal, S., Ferdov, S., Rauwel, E.: A Review on the green synthesis of silver nanoparticles and their morphologies studied via TEM. Adv. Mater. Sci. Eng. 2015, 1-9 (2015) (Article ID 682749)

11. Küünal, S., Kutti, S., Guha, M., Rauwel, P., Wragg, D., Nurk, G., Rauwel, E.: Silver Nanoparticles Study for Application in Green Housing. ECS Trans. 64, 15-24 (2015)

12. Rauwel, E., Karmaoui, M., Rauwel, P. In: Rauwel, E. (ed.) Metal Nanoparticles. Norway (2010) (WO/2012/004573, EP2590765)

13. Rauwel, E., Galeckas, A., Rauwel, P., Sunding, M.F., Fjellvåg, H.: Precursor-Dependent Blue-Green Photoluminescence Emission of ZnO Nanoparticles. J. Phys. Chem. C 115 25227-25233 (2011)

14. Sooklert, K., Chattong, S., Manotham, K., Boonwong, C., Klaharn, I., Jindatip, D., Sereemaspun, A.: Cytoprotective effect of glutaraldehyde erythropoietin on HEK293 kidney cells after silver nanoparticle exposure. Int. J. Nanomed. 11, 597-605 (2016)

15. Crist, B.V.: Handbook of monochromatic XPS spectra, the elements of native oxides, Ames, Iowa, Wiley (2000)

16. Bensch, K., Braun, U., Groenewald, J.Z., Crous, P.W.: The genus Cladosporium. Stud. Mycol. 72, 1-401 (2012)

17. Li, Q., Mahendra, S., Lyon, D.Y., Brunet, L., Liga, M.V., Li, D., Alvarez, P.J.J.: Antimicrobial nanomaterials for water 
disinfection and microbial control: Potential applications and implications. Water Res. 42, 4591-4602 (2008)

18. Jung, W.K., Koo, H.C., Kim, K.W., Shin, S., Kim, S.H., Park, Y.H.: Antibacterial Activity and Mechanism of Action of the Silver Ion in Staphylococcus aureus and Escherichia coli. Appl. Environ. Microbiol. 74, 2171-2178 (2008)

19. Li, W.-R., Xie, X.-B., Shi, Q.-S., Duan, S.-S., Ouyang, Y.-S., Chen, Y.-B.: Antibacterial effect of silver nanoparticles on Staphylococcus aureus. Biometals 24, 135-141 (2011)

20. Marambio-Jones, C., Hoek, E.V.: A review of the antibacterial effects of silver nanomaterials and potential implications for human health and the environment. J. Nanopart. Res. 12, 1531-1551 (2010)
21. Raffi, A.M., Hussain, F., Bhatti, T.M., Akhter, J.I., Hameed, A., Hasan, M.M.: Antibacterial Characterization of Silver Nanoparticles against E. Coli ATCC-15224. J. Mater. Sci. Technol. 24, 192-196 (2008)

22. Dallas, P., Tucek, J., Jancik, D., Kolar, M., Panacek, A., Zboril, R.: Magnetically Controllable Silver Nanocomposite with Multifunctional Phosphotriazine Matrix and High Antimicrobial Activity. Adv. Funct. Mater. 20, 2347-2354 (2010)

23. Chen, X., Huang, X., Zheng, C., Liu, Y., Xu, T., Liu, J.: Preparation of different sized nano-silver loaded on functionalized graphene oxide with highly effective antibacterial properties. J. Mater. Chem. B 3, 7020-7029 (2015) 